\title{
PROPOSIÇÃO DE UM CHECKLIST PARA GESTÃO DE TALUDES EM PROJETOS RODOVIÁRIOS
}

\author{
Ana Patrícia Aranha de Castro ${ }^{1}$
}

\author{
Roger Augusto Rodrigues ${ }^{2}$
}

\author{
Barbara Stolte Bezerra ${ }^{3}$
}

\begin{abstract}
RESUMO
Na gestão da operação das rodovias a análise de estabilidade de taludes não é uma prática corrente. Quando existe a ruptura de um maciço, em especial nas obras rodoviárias onde existe um grande fluxo de veículos, a recuperação dessa área muitas vezes é onerosa e gera prejuízos de dimensões econômicas e sociais imensuráveis como a perda de vidas humanas. Na grande maioria dos casos esta ruptura poderia ser evitada ou pelo menos minimizada, caso houvesse um estudo adequado referente à estabilização dos taludes do entorno da rodovia. Neste artigo apresenta-se um checklist para gestão de projeto rodoviário, visando à estabilização de taludes de uma forma proativa.
\end{abstract}

PALAVRAS-CHAVE: Gestão de projetos. Rodovias. Estabilidade de taludes. Auditoria de segurança.

\section{PROPOSITION OF A CHECKLIST FOR SLOPE MANAGEMENT IN HIGHWAY PROJECTS}

\section{ABSTRACT}

Slope stability analysis is not common practice in a highway operation management. When there is a landslide, mainly in highway where there is a vehicle large flow, the recovery of this area is often costly and generates losses of economic and social dimensions as the immeasurable loss of human lives. In most cases this landslide

\footnotetext{
${ }^{1}$ Engenheira Civil, Universidade Estadual Paulista "Júlio de Mesquita Filho" (FEB-UNESP/Bauru), Mestranda em Engenharia Civil e Ambiental. E-mail: anapattydecastro@hotmail.com.

2 Doutor em Geotecnia, Universidade Estadual Paulista "Júlio de Mesquita Filho" (FEBUNESP/Bauru), Professor Assistente Doutor. E-mail: roger_ar@feb.unesp.br.

${ }^{3}$ Doutora em Engenharia de Transportes, Universidade Estadual Paulista "Júlio de Mesquita Filho" (FEB-UNESP/Bauru), Professora Assistente Doutora. E-mail: barbarabezerra@feb.unesp.br.
} 
could be avoided or reduced, if there was a proper study related to the slope stabilization in highway. This article presents a checklist for a highway project management aiming at the slope stabilization in a proactive manner.

KEY-WORDS: Project management. Highway. Slope stability. Security audit.

\title{
PROPUESTA DE UN CHECKLIST PARA GESTIÓN DE TALUDES EN PROYECTOS DE AUTOPISTAS
}

\begin{abstract}
RESUMEN
En gestión de operación de autopistas el análisis de estabilidad de taludes no es una práctica corriente. Cuando existe la rotura de un macizo de suelo, en especial en autopistas donde existe un gran flujo de vehículos, la recuperación del área muchas veces es onerosa y genera perjuicios de dimensiones económicas y sociales inmensurables como la pierda de vidas humanas. En la gran mayoría de los casos esta rotura podría ser evitada o minimizada, si hubiera un estudio adecuado referente a la estabilización de los taludes del alrededor de la autopista. En este articulo se presenta un checklist para gestión de proyecto de autopistasa apuntando a la estabilización de taludes de una forma proactiva.
\end{abstract}

PALABRAS-CLAVE Gestión de proyectos. Autopistas. Estabilidad de taludes. Auditoría de seguridad.

\section{INTRODUÇÃO}

O crescimento do setor da construção civil tem requerido o desenvolvimento de técnicas que permitam o desenvolvimento de projetos e obras que estejam adequados à realidade imposta por cada tipo de construção. Quando se trata de obras realizadas com maciços de solo ou rocha, cuidados adicionais devem ser tomados, uma vez que estes são materiais com características muito distintas. Diferentemente de outros materiais empregados na construção civil como o concreto e o aço, o solo e a rocha apresentam diversidades tanto referente ao material constituinte quanto às suas propriedades mecânicas e hidráulicas.

Quando existe a ruptura de um maciço, em especial nas obras urbanas ou de grande fluxo, como é o caso de rodovias, a recuperação dessa área exige custos elevados, que poderiam ser evitados ou minimizados, caso um estudo sobre a área tivesse sido realizado de maneira adequada, considerando todos os parâmetros referentes à sua estabilização. Casos de escorregamento, tombamentos, queda de 
Revista Nacional de

Gerenciamento de Cidades

árvores, erosões em maciços de rodovias e ferrovias envolvem situações extremas nas quais os solos e as rochas são solicitados além da sua resistência, gerando um prejuízo de dimensões econômicas e sociais imensuráveis, podendo culminar na perda de vidas humanas, situação esta que não possui reparo técnico nem monetário.

Auditoria de Segurança Viária (ASV) é um processo formal de exame da performance de uma via existente ou futura por um time independente de auditoria. A ASV pode ser usada em qualquer fase do desenvolvimento do projeto viário. A ASV pode também ser usada em qualquer tamanho de projeto desde uma simples interseção até mega-projetos. O AUSTROADS (1994) estabelece checklists para as inspeções de campo da ASV, sendo um dos itens a serem verificados a estabilidade de taludes. No entanto, no checklist proposto pelo AUSTROADS (1994) não há uma descrição detalhada de como deverá ser feita a inspeção da estabilidade de taludes.

Este trabalho tem como objetivo principal propor um checklist específico para a análise de estabilidade de taludes rodoviários para ser utilizado na inspeção de campo durante a realização de uma ASV. Para atingir tal objetivo este trabalho está dividido em cinco seções sendo a primeira a introdução, a segunda refere-se aos objetivos, a terceira à metodologia utilizada, a quarta seção refere-se aos resultados apresentando-se o checklist elaborado e a última seção contém a conclusão.

\section{OBJETIVOS}

O objetivo principal deste trabalho é propor um checklist com itens para inspeção de campo, visando à estabilização de taludes do entorno de rodovias. A norma brasileira de estabilidade de encostas (NBR 11682) prevê a elaboração de laudos de vistoria como procedimento preliminar para elaboração de projeto de estabilização de encostas. No entanto, as recomendações da norma estão voltadas para taludes em um contexto amplo, não trazendo diretrizes específicas para o caso dos taludes em rodovias. 


\section{METODOLOGIA}

O aumento da urbanização e o desenvolvimento de áreas sujeitas a escorregamentos, assim como o desflorestamento e o aumento das taxas de precipitação em curtos períodos causados pelas mudanças climáticas são as principais razões para o aumento dos problemas relacionados à instabilidade de taludes. Os escorregamentos, quando deflagrados em áreas urbanas ou em regiões ocupadas geram custos que podem ser classificados como diretos e indiretos.

Os custos diretos correspondem a reparos de danos, relocação de estruturas, manutenção de obras e instalações de contenções. Já os custos indiretos, envolvem a perda de propriedades, de produtividade industrial e comercial, além da perda de vidas humanas, invalidez física ou trauma psicológico em moradores de locais afetados por escorregamentos.

No caso de obras lineares, tais como estradas, ferrovias, dutovias e outras, os estudos e projetos devem levar em conta a geologia e geomorfologia ao longo do traçado, direção e mergulho das rochas, presença de diversos tipos de solo e outras situações críticas.

Toda obra de engenharia civil assenta-se sobre o terreno e, portanto, requer que o comportamento dos solos e das rochas seja devidamente considerado e analisado. Trabalhos referentes ao comportamento dos solos, mais especificamente, foram desenvolvidos ao longo dos séculos, cujos clássicos são dos autores Coulomb, Rankine e Darcy, entre outros. Entretanto, a existência de falhas em obras geotécnicas no início do século XX, tais como as rupturas do Canal do Panamá e rompimento de grandes taludes em estradas e canais em construção na Europa e nos Estados Unidos, mostrou a necessidade de revisões no procedimento de cálculo de tais obras. PINTO (2006) relata que Karl Terzaghi, em 1936, apontou que não se podiam aplicar aos solos leis teóricas de uso corrente em materiais mais bem definidos, como o concreto e o aço. 
Revista Nacional de

Gerenciamento de Cidades

$\mathrm{Na}$ Geotecnia, a estabilização de taludes pode ser considerada como um dos principais problemas a serem solucionados e controlados. Um talude compreende qualquer superfície inclinada que limita um maciço de terra, de rocha ou de terra e rocha. Pode ser natural, como no caso de encosta, ou artificial, como talude de corte e aterro. Os condicionantes naturais, tais como de ordem geológica, hidrológica ou geotécnica, tornam a estabilidade de um maciço de solo e rocha de grande complexidade. A importância de estudos de estabilidade de taludes deriva do crescente número de obras realizadas, dentre as quais a grande maioria necessita da regularização e contenção de terreno sobre o qual a obra será realizada. Construção de rodovias, ferrovias, barragens de água, aterros sanitários, subsolos, entre outros, necessitam constantemente de investigação geotécnica para garantir que o maciço não se rompa.

Dos tipos de movimento de solo e rocha destacam-se os escorregamentos (slides), rastejo (creep), quedas (falls) e corridas (flows). Os escorregamentos são identificados em função de sua geometria e da natureza do material, podendo ser translacionais ou planares, circulares ou rotacionais e em forma de cunha.

No Brasil, os escorregamentos são frequentes, com destaque para os acidentes de 1966 e 1967, nas encostas do Rio de Janeiro e trechos de rodovias, bem como o deslizamento ocorrido na localidade de Vila Albertina, em Campos do Jordão, São Paulo, em 1972, provocando mortes e grandes prejuízos materiais Recentemente, os escorregamentos ocorridos em Ilha Grande em 2010, Rio de Janeiro, e os de Santa Catarina em 2008, foram de grande destaque na mídia nacional e internacional, devido à grandiosidade do ocorrido e ao grande número de perdas humanas. A Figura 1 ilustra um escorregamento ocorrido em Salvador-BA.

Em relação às causas de um escorregamento, vários fatores podem contribuir como o aumento de peso de talude ou sobrecarga externa, diminuição da resistência ao cisalhamento do material e alterações geométricas. A concomitância desses fatores nas estações chuvosas ou pouco depois, quando a umidade aumenta o peso específico do material e o excesso de água reduz a resistência ao cisalhamento pelo aumento de pressão neutra, explica a ocorrência dos 


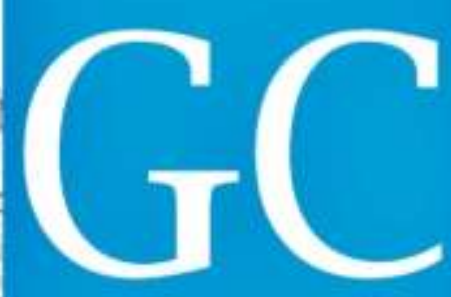

Revista Nacional de

Gerenciamento de Cidades

escorregamentos nos períodos de grande precipitação pluviométrica (Massad, 2003).

Figura 1: Escorregamento de solo em Salvador-BA

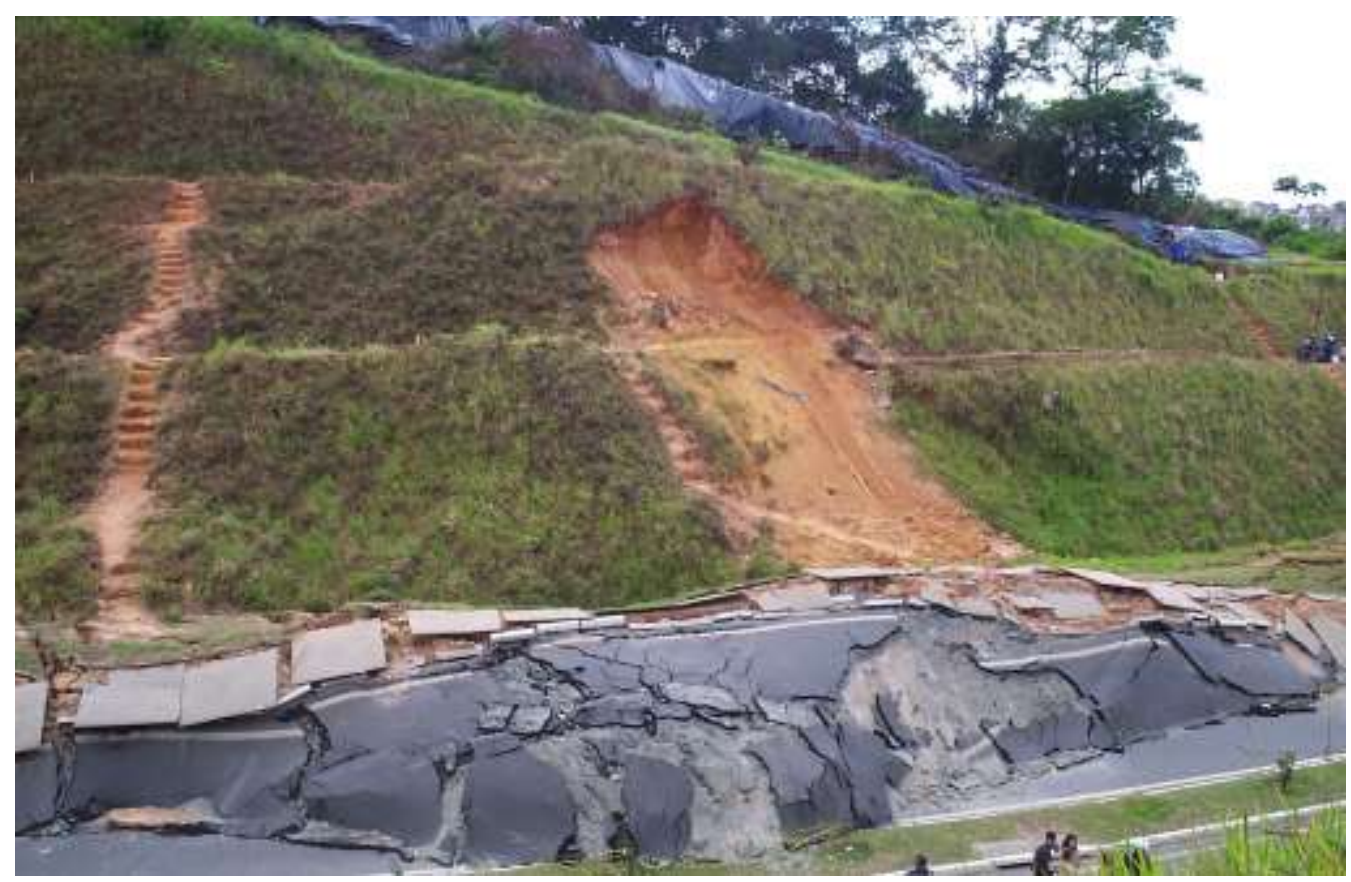

Para análises de estabilidade de um talude, métodos matemáticos e numéricos são utilizados. Do ponto de vista teórico, um talude se apresenta como um material submetido a três campos de força: peso próprio e sobrecargas, fluxo de água e resistência ao cisalhamento. Basicamente, os métodos usados para análises de estabilidade consistem em calcular as tensões em todos os pontos do meio e compará-las com as tensões resistentes (método de análise de tensões) e ou em isolar massas arbitrárias e estudar as condições de equilíbrio, pesquisando o equilíbrio mais desfavorável (método de equilíbrio limite). Das análises de estabilidade de taludes, destacam-se os métodos das cunhas, das lamelas e o do talude infinito. 
Revista Nacional de

Gerenciamento de Cidades

\section{RESULTADOS}

Auditoria de Segurança Viária (ASV) é uma abordagem pró-ativa para melhorar a segurança viária. A prática da segurança viária é reflexo da legislação e atitude de cada cidade, estado e país. Esta prática deve ter como objetivo o detalhamento de normas técnicas para projetos viários e operações de manutenção e de controle de tráfego. No Brasil os programas de redução de acidentes são baseados, em sua grande maioria, no desenvolvimento de medidas que tentam remediar a alta frequência de acidentes nos pontos críticos. Uma nova abordagem é necessária para focar na prevenção de acidentes de uma maneira pró-ativa, antes que os acidentes venham a ocorrer e para garantir que o sistema viário seja seguro. Esta abordagem envolve entre outros componentes o uso da auditoria de segurança viária.

Os países desenvolvidos há algumas décadas descobriram que investimento em segurança viária pode salvar vidas e reduzir custos. A experiência desses países deve servir de exemplo para os países em desenvolvimento ajustar os seus procedimentos e investimentos na segurança viária, e aumentar a consciência do governo, da sociedade e dos engenheiros de tráfego. (Ferraz et al, 2012). No Brasil não se pode mais aceitar os altos números de acidentes, feridos e mortos no trânsito. É um alto preço a ser pago por esta negligência: vidas, dinheiro e tempo no sistema de saúde.

AUSTROADS (1994) define a ASV com um exame formal da futura via ou projeto viário, de uma via existente ou qualquer outro projeto que interaja com os usuários da via, nos quais um independente e qualificado time de auditores relata os potencias acidentes e performance de segurança do projeto.

Um dos principais objetivos atualmente da segurança viária é a redução do número de acidentes e o número de causalidades. A aplicação dos princípios de segurança viária no planejamento, implantação, melhoramento ou manutenção de vias, contribuem para a prevenção de acidentes. 
Revista Nacional de

Gerenciamento de Cidades

ASV é uma excelente ferramenta para identificar pontos potenciais de problemas de segurança para todos os usuários da via e assegurar que medidas para eliminar ou reduzir os problemas foram totalmente consideradas.

Os usuários devem viajar num produto com segurança consistente, onde fatores adversos da via que contribuem para acidentes são reduzidos, dessa forma a ASV é um procedimento para ajudar a alcançar isso. A ASV dá um status maior à segurança viária no decorrer do projeto e atua como meio de informar os engenheiros dos conhecimentos atuais sobre segurança. As recomendações dos auditores não são estabelecidas pela checagem de elementos individuais do projeto contra os padrões e normas existentes, mas na consideração do esquema como um todo e como isso pode afetar a segurança geral, ou decidir o que fazer quando há conflitos entre as normas.

A ASV pode ser conduzida em uma ou mais das cinco etapas de um projeto específico: estudo de viabilidade, projeto preliminar, projeto definitivo, antes da abertura ao tráfego e depois da abertura ao tráfego (via existente). Neste trabalho o foco está na ASV após a abertura ao tráfego, que tem como objetivo checar como a via está sendo atualmente usada, se há alguma deficiência do conceito do projeto ou da implementação de detalhes. Também a ASV pode ser aplicada a vias ou malhas viárias para identificar características que podem ser perigosas e que podem levar à um acidente ou aumentar a consequência do acidente ou permitir ferimentos adicionais. Nesta etapa a ASV é também conhecida como auditoria de revisão ou monitoramento da segurança.

De acordo com AUSTROADS (1994), "O processo da ASV pode ser aplicado para a malha viária existente - tanto de um modo específico para uma rota (que trabalha os assuntos de segurança de forma detalhada), quanto de um modo mais amplo para uma malha viária (que trabalha assuntos de segurança de forma ampla)". O processo de auditoria quando aplicado a vias existentes é chamado algumas vezes de outro nome como revisão ou avaliação (por exemplo, revisão da malha viária, ou avaliação da segurança viária) para enfatizar a diferença entre a auditoria da etapa de projeto. 
Os checklists são ferramentas úteis para conduzir a ASV, e não são instrumentos rígidos. Ao contrário, devem ser um guia flexível e um lembrete de coisas para procurar, levando o time de auditores a uma avaliação compreensiva do projeto. Os checklists:

- São formulados para guiar o processo;

- Podem ser modificados para se adequar a etapa da auditoria e do projeto;

- Devem ser considerados como uma ajuda, e não como produto final;

- Devem ser considerados como uma ferramenta, e não como um requerimento rígido.

Nos checklists estabelecidos pelo AUSTROADS (1994), no item "Tópicos Gerais" estão incluídos os seguintes elementos descritos abaixo:

- Escopo do projeto, função e tipo de tráfego

- Tipo e grau de acesso às propriedades e áreas de expansão

- Significantes áreas de expansão adjacentes

- Futuras duplicações de pista e/ou realinhamentos

- Efeitos na malha viária

- Drenagem

- Condições climáticas

- Serviços

- Paisagismo

- Estabilidade de cortes e aterros

- Estabilidade de taludes

- Drenagem de taludes

- Veículos de emergência e acessos

- Acostamento e delineação

- Superfície

- Contraste das marcas de sinalização

- Instalações perigosas

- Características naturais 
Revista Nacional de

Gerenciamento de Cidades

No entanto, no checklist proposto pelo AUSTROADS (1994) não há uma descrição detalhada de como deverá ser a análise da estabilidade de taludes. Além disso, a NBR 11682 não prevê a elaboração de laudos de vistoria para as etapas de manutenção e de monitoramento de uma obra, mas apenas para a etapa de procedimentos preliminares necessários para a elaboração do projeto de estabilização.

$\mathrm{Na}$ etapa de manutenção de uma obra em talude é importante que o executor forneça um manual de usuário para o proprietário. Neste manual devem constar as providências para manutenção, tanto no que refere ao serviço a ser realizado quanto à periodicidade das avaliações que devem ser no mínimo semestrais. Tais recomendações devem ter por objetivo manter as características originais do projeto executado. Nesta fase, deve ser considerada basicamente a verificação de anomalias como trincas, obstrução e limpeza periódica do sistema de drenagem e erosões. Já o monitoramento da obra deve ser executado sempre que julgado necessário pelo engenheiro responsável, como dado relevante para garantia da estabilidade do talude. Para isso, deve-se definir a metodologia de instalação de instrumentação e a periodicidade das leituras, assim como a elaboração de relatório técnico de acompanhamento do monitoramento para ser encaminhado ao interessado.

Baseando-se na NBR 11682 e na possibilidade de aplicação em etapas de manutenção e monitoramento de uma obra foi elaborado o checklist apresentado nas Figuras 2 e 3.

Com o auxílio deste checklist é possível estabelecer periodicidade de manutenções e monitoramento de taludes identificados como críticios nas inspeções de ASV. Dessa forma, o checklist é uma ferramenta útil para a gestão de projetos rodoviários. O arquivamento dos resultados da inspeção da ASV e dos checklists torna possível o monitoramento dos taludes rodoviários ao longo do tempo. Estas informações poderão ainda estar georreferenciadas facilitando a espacialização dos dados para melhor gestão dos projetos rodoviários. 
Figura 2: Checklist para análise de estabilidade de taludes

\section{CHECKLIST}

\begin{tabular}{|c|c|c|c|c|c|c|c|c|c|}
\hline \multicolumn{10}{|c|}{ CADASTRAMENTO } \\
\hline \multicolumn{3}{|l|}{ Local: } & \multicolumn{7}{|l|}{ Rodovia: } \\
\hline \multicolumn{2}{|c|}{ km (PNV): } & & \multicolumn{2}{|c|}{$\mathrm{km}$ (existente): } & & & \multicolumn{3}{|l|}{ Sentido: } \\
\hline \multicolumn{2}{|c|}{ Coodenadas: } & \multicolumn{2}{|l|}{ UTM } & \multicolumn{6}{|l|}{ Datum: } \\
\hline Ponto 1: & $\begin{array}{l}\mathrm{N} \\
\mathrm{E}\end{array}$ & & Ponto 2: & $\begin{array}{l}\mathrm{N} \\
\mathrm{E}\end{array}$ & & & Ponto 3: & $\begin{array}{l}\mathrm{N} \\
\mathrm{E}\end{array}$ & \\
\hline \multicolumn{2}{|c|}{ Cadastramento anterior } & & ( ) $\mathrm{Sim}$ & Data & 1 & ( & ( ) Não & & \\
\hline \multicolumn{2}{|c|}{ Em caso positivo: } & Houve e & volução d & problema & ( & ) $\mathrm{Sim}$ & & & ) Não \\
\hline \multicolumn{5}{|c|}{$\begin{array}{l}\text { Foram realizadas obras } \\
\text { Especificar: }\end{array}$} & ( & ) $\operatorname{Sim}$ & & ( & ) Não \\
\hline \multicolumn{5}{|c|}{ Existe projeto de obra de estabilização } & ( & ) $\mathrm{Sim}$ & & ( & ) Não \\
\hline \multicolumn{5}{|c|}{ Existe necessidade de monitoramento } & ( & ) $\mathrm{Sim}$ & & ( & ) Não \\
\hline
\end{tabular}

\begin{tabular}{|l|l|l|}
\hline \multicolumn{2}{|c|}{ DADOS DO TALUDE } \\
\hline Altura $(\mathrm{m}):$ & Volume aproximado de material $\left(\mathrm{m}^{3}\right):$ \\
\hline Extensão $(\mathrm{m}):$ & Inclinação $\left({ }^{\circ}\right)$ : \\
\hline Declividade (\%): & \multicolumn{1}{l}{ ( ) Não } \\
\hline Presença de água & $\begin{array}{l}\text { ( ) Sim } \\
\text { ( ) Áreas saturadas }\end{array}$ & $($ ) Surgências localizadas \\
\hline
\end{tabular}

\section{CARACTERIZAÇÃO GEOLÓGICO - GEOTÉCNICA}

\begin{tabular}{lll} 
( ) Solo arenoso & ( ) Rocha \\
( ) Solo siltoso & $($ ) Solo mole \\
( ) Solo argiloso & & \\
\hline
\end{tabular}

\begin{tabular}{|c|c|c|c|}
\hline \multicolumn{4}{|c|}{ TIPO DE PROBLEMA } \\
\hline & ) EROSÃO & ( ) ESCORREGAMENTO & ( ) QUEDA DE BLOCOS \\
\hline & ) em sulcos & ( ) circular & ( ) por rolamento \\
\hline & ) ravinas & ( ) em cunha & ( ) por desplacamento \\
\hline & ) voçoroca & ( ) translacional & \\
\hline
\end{tabular}

\begin{tabular}{|c|c|}
\hline & OUTROS PROBLEMAS \\
\hline Especificar: & \\
\hline
\end{tabular}

Data:

Responsável técnico: 
Figura 3: Checklist para análise de estabilidade de taludes

\section{CHECKLIST}

\begin{tabular}{|cc|}
\hline \multicolumn{2}{|c|}{ GRAVIDADE } \\
\hline ( ) Nível 1 - Não oferece perigo para o tráfego & $\left(\begin{array}{l}\text { ) Nível 3 - Em evolução, perigo a } \\
\text { curto/médio prazo para o tráfego }\end{array}\right.$ \\
$\begin{array}{c}\text { prazo para o tráfego } \\
\text { ( ) Nível } 2 \text { - Pode oferecer perigo a longo }\end{array}$ & $\begin{array}{c}\text { Nível } 4 \text { - Em evolução, com } \\
\text { perigo imediato para o tráfego }\end{array}$ \\
\hline
\end{tabular}

\section{DIAGNÓSTICO DE PROBLEMAS (CAUSAS PROVÁVEIS)}

\begin{tabular}{|cc}
\hline ( ) Deficiência de proteção superficial & ( ) Descontinuidades do maciço \\
( $\quad$ ) Deficiência de sistema de drenagem & ( ) Faltam informações suficientes \\
superficial (canaletas/descida d'água) & \\
( ) Desestabilização por desagregação & Havendo necessidade de investigações \\
superficial & complementares especificar: \\
( Inclinação do maciço & \\
\hline
\end{tabular}

\section{MEDIDAS E OBRAS}

Medidas e serviços a serem implantados:

\section{CROQUI (planta e elevação)}


Revista Nacional de

Gerenciamento de Cidades

\section{CONCLUSÃO}

Neste trabalho um checklist específico para a análise de estabilidade de taludes rodoviários foi proposto para ser utilizado na inspeção de campo durante a realização de uma Auditoria de Segurança Viária, ASV.

A instabilidade de taludes de solo e rocha consiste em um dos principais problemas da engenharia civil. No Brasil, os escorregamentos são frequentes e acarretam importantes prejuízos à sociedade e ao poder público. Além disso, eventos deflagrados em determinadas épocas do ano tem causado danos irreparáveis associados à perda de vidas humanas.

A ASV é uma importante aliada na gestão da segurança rodoviária, no entanto, ainda é feita de maneira incipiente no Brasil. A elaboração de um checklist específico para a estabilidade de taludes rodoviários é um passo importante para o estabelecimento dessa prática no Brasil, sendo uma ferramenta útil para acompanhar, realizar a manutenção e monitoramento de taludes, especialmente os considerados críticos, no intuito de prevenir acidentes.

\section{REFERÊNCIAS}

Associação Brasileira de Normas Técnicas NBR 11682 - Estabilidade de Encostas, ABNT, 2009. AUSTROADS. Road Safety Audits, AU, 1994.

FERRAZ, A.C.P.; RAIA Jr., A.A.; BEZERRA, B. S.; BASTOS, J. T.; RODRIGUES, K. Segurança Viária. Ed. São Francisco, 2012.

MASSAD, F. Obras de Terra - Curso Básico de Geotecnia. Editora Oficina de Textos, 2003.

PINTO, C.S. Curso Básico de Mecânica dos Solos. Editora Oficina de Texto, 3a edição, 2006. 